\title{
VOCs Measurements in Residential Buildings: Quantification via Thermal Desorption and Assessment of Indoor Concentrations in a Case-Study
}

\author{
Sabrina Rovelli ${ }^{1, *}$, Andrea Cattaneo ${ }^{1}{ }^{\circledR}$, Arianna Fazio ${ }^{1}$, Andrea Spinazzè ${ }^{1}{ }^{1}$,

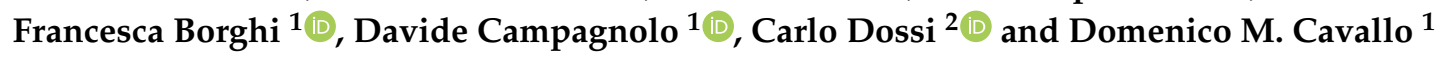 \\ 1 Department of Science and High Technology, University of Insubria, 22100 Como, Italy; \\ andrea.cattaneo@uninsubria.it (A.C.); arianna.fazio@hotmail.com (A.F.); \\ andrea.spinazze@uninsubria.it (A.S.); f.borghi2@uninsubria.it (F.B.); \\ davide.campagnolo@uninsubria.it (D.C.); domenico.cavallo@uninsubria.it (D.M.C.) \\ 2 Department of Theoretical and Applied Sciences, University of Insubria, 21100 Varese, Italy; \\ carlo.dossi@uninsubria.it \\ * Correspondence: sabrina.rovelli@uninsubria.it; Tel.: +39-031-238-6628/6629
}

Received: 29 October 2018; Accepted: 22 January 2019; Published: 1 February 2019

\begin{abstract}
Volatile organic compounds (VOCs) represent one of the most important categories of pollutants, influencing the air quality and human health and well-being in indoor environments. In the present study, 12 selected VOCs were sampled using Tenax TA tubes and analyzed by thermal desorption combined with gas chromatography and a flame ionization detector (TD-GC-FID). The TD-GC-FID method was optimized to obtain the separation of all the analytical peaks (including $m$ - and $p$-xylene) and a satisfactory sensitivity, with low detection (between 0.14 and $0.31 \mathrm{ng}$ ) and quantification (between 0.47 and $1.02 \mathrm{ng}$ ) limits. The whole procedure was firstly assessed with the analysis of four co-located tubes exposed at an outdoor monitoring site, with results that revealed a very low inter-tubes variability (relative standard deviations of parallel measurements $<5 \%$ ). Then, the measurement protocol was used to quantify the indoor concentrations of the target VOCs in nine different homes during the dishwasher washing cycle. The most abundant detected VOC in all dwellings was d-limonene (mean: $231 \mu \mathrm{g} / \mathrm{m}^{3}$; maximum: $611 \mu \mathrm{g} / \mathrm{m}^{3}$ ). All the other compounds were monitored at concentration levels one or two orders of magnitude lower than d-limonene, and were generally comparable with those found in the scientific literature. In terms of health concerns, the measured concentrations were always well below the safe levels established for the protection of the general population in living environments.
\end{abstract}

Keywords: indoor VOCs; limonene; terpenes; air monitoring; indoor air quality; VOCs quali-quantitative analysis

\section{Introduction}

Human exposure to airborne pollutants in indoor environments is an important health concern because people spend on average $80-90 \%$ of their time in confined environments, which greatly contributes to total daily personal exposure [1]. The residential environment is, in turn, one of the major settings for the indoor exposure since two thirds of the time indoors is generally spent at home.

The indoor air quality (IAQ) is strictly dependent on the occurrence of several chemicals, or classes of chemicals, among which volatile organic compounds (VOCs) represent one of the most important categories of pollutants influencing the air quality, and consequently, human well-being and health [1-4]. VOCs are classified as organic compounds having a boiling point between $50{ }^{\circ} \mathrm{C}$ and $260^{\circ} \mathrm{C}$. These compounds can be emitted into the atmosphere from anthropogenic or biogenic sources, 
and may also be formed as products of the atmospheric transformation of other VOCs [5]. Many VOCs, especially those containing reactive $\mathrm{C}=\mathrm{C}$ double bonds (e.g., unsaturated terpenes and terpenoids such as d-limonene), can be oxidized to generate a wide variety of both gas- and particle-phase compounds which are sometimes more harmful (e.g., formaldehyde) than the original ones [6-8]. As extensively reported in the literature on potential indoor reactivity as the basis of models or field studies [9-11], terpene oxidation can be driven by reactions with hydroxyl radicals, ozone, nitrate radicals or via photolysis, and for some monoterpenes, such as $a$-pinene and d-limonene, the reaction with ozone is likely to be the predominant mechanism in the atmosphere. In terms of atmospheric chemistry, terpene ozonolysis is an extremely complex process, which involves different reaction steps leading to the formation of a series of oxidation products (formaldehyde, acetone, hydrogen peroxide as well as different gases having a low vapor pressure that can subsequently self-nucleate to form ultrafine particles $(<0.1 \mu \mathrm{m})$ or condense on existing larger particles) [7].

In recent years, different studies have documented consistent associations between VOC exposure and the occurrence of short- and long-term adverse effects on human health and comfort [12,13]. Among the most commonly studied VOCs in indoor environments are benzene, toluene, ethylbenzene, xylenes (BTEX), together with styrene, n-hexane, 2-ethylexanol, 2-butoxyethanol, aldehydes (e.g., formaldehyde, acetaldehyde, benzaldehyde, acrolein) and some terpenes (mainly $\alpha$-pinene and d-limonene). All these compounds are known for their potential impact on human health $[13,14]$ or because they are typically emitted from indoor sources [15]. The broad presence of these compounds in indoor settings is indeed due to their volatility, but also to the fact that they have been widely used in a large number of household products like paints, solvents, detergents, varnishes, cleaning products and electronic devices (e.g., printers or photocopiers) [16-18]. Moreover, some VOCs are emitted from outdoor sources, such as traffic, and penetrate indoor (BTEX are the most representative example). This means that the outdoor pollution, especially in urban environments, can significantly affect the quality of indoor air [19].

In general, VOCs are ubiquitous in any built environment, but their speciation, abundance and concentration may vary in a relevant way because of different factors (e.g., products used and building material/emission sources, personal activities and behavior, outdoor pollution, seasonality, geographical and/or climatic differences) [20]. Furthermore, it is noteworthy that in recent decades there has been a significant change in the use of consumer products and building materials, as well as a move towards energy-efficient buildings characterized by improved insulation and reduced air leakage and ventilation, with a consequent impact on both concentrations and types of VOCs found indoors [21,22].

In light of these considerations, the monitoring of indoor VOCs still represents a crucial tool for (i) the exposure assessment of the general population and/or workers in living as well as occupational environments; (ii) the epidemiological research, and (iii) the risk management and improvement of IAQ based on source identification.

A large number of different investigations exist for a variety of private and public indoor environments and for the most common pollutants like BTEX, styrene, terpenes $[3,4,9,18,23,24]$, but there are also other priority or emerging chemicals for which the available information is still too limited. Moreover, up to now, there are no national or European legislations that explicitly indicate harmonized protocols for the IAQ monitoring and management.

VOCs sampling is usually carried out by passive sampling, which presents different advantages such as lower costs of monitoring devices, no need of electrical power and longer sampling period, providing in this way more information for chronic exposure purposes. Nevertheless, when significant temporal variations are expected or lower monitoring periods are needed (e.g., to monitor hourly variability), the use of an active sampling followed by thermal desorption and gas chromatography analysis with a flame ionization detector or a mass spectrometer (TD-GC-FID or TD-GC-MS) generally represents one of the best compromises [25-30]. As reported in the literature, different thermal 
desorption coupled to GC-MS or GC-FID methods were developed and validated for a wide range of volatile compounds in air [26-29].

In the present study, 12 target VOCs (benzene, toluene, ethylbenzene, $o-, m-, p$-xylene, ethylene glycolbutyl ether (EGBE), 2-ethylhexanol, styrene, benzyl alcohol, $\alpha$-pinene and d-limonene) were selected as compounds of interest because they may be emitted in high rates from products widely used at homes (e.g., cleaning and care products, detergents, solvents) and/or because they are reactive (e.g., terpenes), and under certain conditions, can lead to the formation of secondary compounds in the atmosphere. Moreover, most of these chemical species are notorious for their potential impact on human health and comfort $[13,14]$. In the last decade, the European Commission (EC) highlighted the need of a strategy that will lead to the identification and regulation of priority indoor chemical compounds [31]. In this regards, the EC strategy document classified benzene in Group 1 (high priority chemicals), toluene, xylenes and styrene in Group 2 (second priority chemicals) and $\alpha$-pinene and d-limonene in Group 3 (chemicals requiring further research with regard to human exposure or dose response) [31].

The concentration levels of the selected compounds were preliminary investigated outdoors and then in nine different homes in Como (Northern Italy) during a dishwasher washing cycle, which was supposed to be potentially related to an important emission of some gaseous pollutants into the atmosphere (e.g., fragrances as d-limonene or $\alpha$-pinene).

The target VOCs were subject to an active solid adsorbent-based sampling and a fully quantitative determination using a TD-GC-FID method that was properly optimized before the sampling campaign, and tested under real on-field conditions at an outdoor site. Starting from a methodology already known and used in the literature, different steps were indeed required for method optimization to get reliable results, ensuring the best peaks resolution and a satisfactory sensitivity, with low detection and quantification limits for all the investigated compounds.

Data obtained from the examined case-study were provided as a preliminary and exploratory survey, (i) to verify the hypothesis for which the investigated scenario could represent-or not-a potential health risk, and (ii) to consequently promote, where necessary, future and more exhaustive IAQ investigations.

\section{Experimental Section}

\subsection{Vocs Sampling and Analysis by TD-GC-FID: Method Optimization}

\subsubsection{Solid-Adsorbent Based Sampling}

As previously stated, in the present study the monitoring of volatile compounds in the indoor air was accomplished by an active sampling on stainless steel sorbent tubes (Perkin-Elmer, Wilton, CT, USA) packed with Tenax TA (200 mg, 60/80 mesh, Supelco Park, Bellefonte, PA, USA) and connected to a sampling pump unit (AirCheck XR 5000, SKC, Inc., Eighty Four, PA, USA) set at a flow rate of $0.1 \mathrm{~L} / \mathrm{min}$.

Before the first use, Tenax TA tubes were subject to a thermal cleaning process (two cycles at $280{ }^{\circ} \mathrm{C}$ for $30 \mathrm{~min}$ each one) under a flow rate of helium $(30 \mathrm{~mL} / \mathrm{min})$ and immediately sealed to prevent any kind of contamination with Swagelock end caps fitted with PTFE ferrules and precleaned by rinsing $50: 50$ acetone/hexane followed by baking at $150{ }^{\circ} \mathrm{C}$ for $90 \mathrm{~min}$.

After any sampling and thermal desorption process, Tenax tubes were reconditioned with a thermal treatment at $280^{\circ} \mathrm{C}$ for $6 \mathrm{~min}$ and resealed again until subsequent reuse.

\subsubsection{Chemicals and Multistandard Solutions}

Standards of the selected VOCs (benzene, toluene, ethylbenzene, $o_{-}, m-, p$-xylene, EGBE, 2-ethylhexanol, styrene, benzyl alcohol, $\alpha$-pinene and d-limonene) were purchased as pure chemicals from Sigma Aldrich (Sigma Aldrich, Milwaukee, WI, USA) with purity always higher than $98 \%$. 
A multistandard stock solution was prepared by pipetting $100 \mu \mathrm{L}$ of each liquid standard into $50 \mathrm{~mL}$ of pure heptane (Sigma Aldrich, Milwaukee, WI, USA), to have an individual VOC concentration of about $1800 \mu \mathrm{g} / \mathrm{mL}$. In the case of toluene, the concentration has been doubled, because this compound is generally present at higher concentration levels in the environment. The multistandard stock solution was then diluted in heptane to obtain four VOC standards ranging from approximately $11 \mu \mathrm{g} / \mathrm{mL}$ to approximately $85 \mu \mathrm{g} / \mathrm{mL}$. All standard solutions were freshly prepared the first day of use, transferred into $2 \mathrm{~mL}$ vials, and then stored at $4{ }^{\circ} \mathrm{C}$ in darkness.

Calibration was performed by spiking four blank sampling tubes with $1 \mu \mathrm{L}$ of each multistandard solution, respectively, so that the investigated VOCs were present in a mass range from approximately $11 \mathrm{ng}$ to approximately $85 \mathrm{ng}$ into the respective tubes (22-170 $\mathrm{ng}$ for toluene). Pure heptane was used as calibration blank. The spiked tubes were subsequently loaded onto the tray of the thermal desorber and analyzed applying the same analytical program optimized for atmospheric samples, as described in Section 2.1.3, to obtain calibration curves of the relationship between the analyte masses ( $x$ variable) and the integrated peak areas (y variable).

\subsubsection{Analytical Instrumentation and Analysis}

VOCs analyses were carried out using an automated thermal desorber (ATD 400, Perkin Elmer, Norwalk, CT, USA) operated in the two-stage desorbing mode and coupled to a GC-FID instrumentation. The GC system (HRGC MEGA 2 series, MFC 800, Fisions Instruments) was equipped with a polar capillary column (Supelcowax-10, $60 \mathrm{~m} \times 0.53 \mathrm{~mm}$, film thickness $1 \mu \mathrm{m}$ ) and a Flame Ionization Detector (FID, EL-980, Fisions Instruments) set at $250^{\circ} \mathrm{C}$.

The primary desorption from Tenax tubes was performed at $280{ }^{\circ} \mathrm{C}$ for 6 min with a helium flow rate of $20 \mathrm{~mL} / \mathrm{min}$. During this primary desorption step, the eluted VOCs were transferred from the tube to a cryofocusing trap set at $-30{ }^{\circ} \mathrm{C}$. The secondary desorption started with rapidly heating the cold trap from $-30{ }^{\circ} \mathrm{C}$ to $300{ }^{\circ} \mathrm{C}$. In this way, the cryofocused VOCs were desorbed for a second time and injected onto the capillary column via a transfer line heated at $200{ }^{\circ} \mathrm{C}$. Once onto the gas-chromatographic column, the analytes were subject to the following temperature program, with a total analytical time of $60 \mathrm{~min}$ : a first isotherm at $50^{\circ} \mathrm{C}$ for $5 \mathrm{~min}$, followed by a run from 50 to $100^{\circ} \mathrm{C}$ at $2{ }^{\circ} \mathrm{C} / \mathrm{min}$, a further run from 100 to $200{ }^{\circ} \mathrm{C}$ at $10{ }^{\circ} \mathrm{C} / \mathrm{min}$ and a final isotherm at $200{ }^{\circ} \mathrm{C}$ for $10 \mathrm{~min}$ with helium as the carrier gas and nitrogen as the auxiliary gas. The final operating conditions of the TD-GC-FID instrumentation are summarized in Table 1.

Table 1. Operating parameters of the TD-GC-FID instrumentation.

\begin{tabular}{cc}
\hline & Automated Thermal Desorber (ATD) \\
\hline Carrier gas & Helium \\
Primary desorption & $280{ }^{\circ} \mathrm{C}, 6 \mathrm{~min}$ \\
Total primary desorption flow-rate & $20 \mathrm{~mL} / \mathrm{min}$ \\
Inlet split flow-rate & $6.8 \mathrm{~mL} / \mathrm{min}$ \\
Outlet split flow-rate & $6.5 \mathrm{~mL} / \mathrm{min}$ \\
Valve temperature & $200^{\circ} \mathrm{C}$ \\
Cold trap temperature & $-30^{\circ} \mathrm{C}$ \\
Secondary desorption & $300{ }^{\circ} \mathrm{C}, 6 \mathrm{~min}$ \\
Transfer line temperature & $200^{\circ} \mathrm{C}$ \\
GC system & \\
Carrier gas & Helium $(1 \mathrm{~mL} / \mathrm{min})$ \\
Auxiliary gas & Nitrogen $(30 \mathrm{~mL} / \mathrm{min})$ \\
Total run time & $60 \mathrm{~min} / \mathrm{min}$ to $200{ }^{\circ} \mathrm{C} ; 200{ }^{\circ} \mathrm{C}, 10 \mathrm{~min}$ \\
FID temperature & $50^{\circ} \mathrm{C}, 5 \mathrm{~min} ; 2^{\circ} \mathrm{C} / \mathrm{min}$ to $100{ }^{\circ} \mathrm{C} ; 10{ }^{\circ} \mathrm{C}$ \\
\hline
\end{tabular}

Qualitative identification of target VOCs in real samples was based on the match of the retention times between atmospheric samples and the multistandard solutions. The Chrom-Card software package was used to control all the GC parameters, to acquire the current chromatographic analysis and to obtain the integrated peak area for the quantitative determination of each compound of interest. 
Limits of detection (LODs) and quantification (LOQs) were determined as 3 and 10 times the standard deviation of the background noise, respectively, divided by the slope of calibration lines. LODs and LOQs results were expressed both as mass (ng) and concentration in air $\left(\mu \mathrm{g} / \mathrm{m}^{3}\right)$, considering the average air volume sampled during the field campaigns carried out in residential buildings (2-h sampling period at a flow rate of $0.1 \mathrm{~L} / \mathrm{min}$, see Section 2.2).

Finally, the whole method-from air sampling to thermal desorption and chromatographic analysis-was assessed under real on-field conditions, which is the best approach to verify whether other external variables, including the inter-tubes variability, could somewhat affect the trueness of concentration results. Field measurements were carried out with four Tenax TA tubes exposed in parallel over a 4-h sampling period at an outdoor urban background site (flow rate: $0.1 \mathrm{~L} / \mathrm{min}$ ). After sampling, the tubes were immediately sealed to avoid leakages and analyzed on the same day of collection.

\subsection{Case-Study in Residential Buildings}

The optimized TD-GC-FID protocol was subsequently applied for the analysis of indoor air samples. In particular, nine different residential buildings in Como (Northern Italy) were randomly selected and investigated to assess the indoor concentrations of the target VOCs during the dishwasher washing cycle, which was supposed to be one of the household activities potentially related to high emissions of some gaseous pollutants (e.g., fragrances as d-limonene or $\alpha$-pinene) [32,33].

For these purposes, an active sampling line (flow rate: $0.1 \mathrm{~L} / \mathrm{min}$ ) was placed in the kitchen area of each house at a height of approximately $1.7 \mathrm{~m}$ and ambient sampling was performed following a standardized sampling protocol, which was arbitrarily established to ensure methodological harmonization and make the results mutually comparable. Specifically, samplings were started at the beginning of the washing cycle, then extended for $15 \mathrm{~min}$ at the end of the cycle with the dishwasher closed and again for other $15 \mathrm{~min}$ after the dishwasher opening, for a total sampling duration always less than $2 \mathrm{~h}$ and $30 \mathrm{~min}$ not to exceed the breakthrough volume of Tenax tubes (Table 2). After sampling, Tenax tubes were immediately sealed to avoid leakages and stored at $<4{ }^{\circ} \mathrm{C}$ until analysis (which was performed within 1 week). All indoor samples were collected during the last week of January 2018. Some details about the monitoring sites and washing cycles are reported in Table 2. Products 1, 2, 3 and 6 were cleaning tablets, whereas products 4 and 5 were liquid detergents having different chemical compositions. Limonene was always present as an additive ingredient, in a percentage of generally $<5 \%$.

Table 2. General information about the monitoring sites and washing cycles. *: limonene always present as an additive ingredient, in a percentage of generally $<5 \%$.

\begin{tabular}{|c|c|c|c|c|c|}
\hline $\begin{array}{l}\text { Sample } \\
\text { Number }\end{array}$ & Type of Site and Location & Floor & $\begin{array}{c}\text { Duration of the } \\
\text { Dishwashing Cycle } \\
\text { (min) }\end{array}$ & $\begin{array}{c}\text { Total } \\
\text { Sampling } \\
\text { Time (min) }\end{array}$ & $\begin{array}{l}\text { Type of } \\
\text { Product } \\
\text { Used * }\end{array}$ \\
\hline 1 & $\begin{array}{l}\text { Suburban site, on a private } \\
\text { garden. Main road over } 100 \mathrm{~m}\end{array}$ & Ground floor & 50 & 80 & Type 1 \\
\hline 2 & $\begin{array}{l}\text { Suburban site, on a private } \\
\text { courtyard. Main road over } 100 \mathrm{~m}\end{array}$ & 1st floor & 65 & 95 & Type 2 \\
\hline 3 & $\begin{array}{l}\text { Suburban site, on a private } \\
\text { courtyard. Main road over } 100 \mathrm{~m}\end{array}$ & 1st floor & 85 & 115 & Type 2 \\
\hline 4 & $\begin{array}{l}\text { Urban site, on a private garden. } \\
\text { Main road over } 50 \mathrm{~m}\end{array}$ & 1st floor & 85 & 115 & Type 3 \\
\hline 5 & $\begin{array}{l}\text { Suburban site, on a private } \\
\text { courtyard. Main road over } 100 \mathrm{~m}\end{array}$ & 1st floor & 95 & 125 & Type 4 \\
\hline 6 & $\begin{array}{l}\text { Rural site, on a private courtyard } \\
\text { and near a private garden. Main } \\
\text { road over } 150 \mathrm{~m}\end{array}$ & 1st floor & 45 & 75 & Type 2 \\
\hline 7 & Rural site, on a private courtyard & 1st floor & 85 & 115 & Type 4 \\
\hline 8 & Rural site, on a private courtyard & 1st floor & 30 & 60 & Type 5 \\
\hline 9 & Rural site, on a private garden & Ground floor & 90 & 120 & Type 6 \\
\hline
\end{tabular}


Information on the air exchange rates was not collected, but in all the kitchens, windows were kept closed and extraction hoods turned off during sampling.

\section{Results and Discussion}

The assessment of TD-GC-FID method and the results obtained from indoor investigations in residential buildings are presented and discussed below.

\subsection{TD-GC-FID Method Optimization}

Selectivity. The temperature program used to separate VOC analytes was optimized to obtain the best peak resolution. Under the optimized parameters, chromatographic separation was satisfactory, with acceptable tailing observed for all the compounds of interest (Table 3). Also $m$ - and $p$-xylene, which typically have overlapping peaks and are more difficult to separate $[18,34,35]$, were separated at baseline, making their individual quantification possible (Table 3).

Table 3. List of the investigated compounds, with the respective retention times under the optimized TD-GC-FID operating parameters. The range of each calibration curve with the respective correlation coefficients $\left(\mathrm{R}^{2}\right)$ and the calculated LODs and LOQs are also reported. Finally, the percent relative standard deviations (\%RSD) of four Tenax TA tubes exposed in parallel are shown. n.d.: not detected.

\begin{tabular}{|c|c|c|c|c|c|c|}
\hline Compound & $\begin{array}{l}\text { Retention } \\
\text { Time (min) }\end{array}$ & $\begin{array}{c}\text { Mass Range for } \\
\text { Calibration } \\
\text { Curve (ng) }\end{array}$ & $\mathbf{R}^{2}$ & $\begin{array}{c}\text { LOD } \\
\left(\mathrm{ng}-\mu \mathrm{g} / \mathrm{m}^{3}\right)\end{array}$ & $\begin{array}{c}\text { LOQ } \\
\left(\mathrm{ng}-\mu \mathrm{g} / \mathrm{m}^{3}\right)\end{array}$ & $\%$ RSD \\
\hline Benzene & 9.5 & $9.7-79.1$ & 0.9987 & $0.21-0.018$ & $0.70-0.058$ & 10.4 \\
\hline$\alpha$-Pinene & 12.7 & $9.6-78.4$ & 0.9916 & $0.31-0.026$ & $1.02-0.085$ & n.d. \\
\hline Toluene & 14.1 & $19.6-160.0$ & 0.9998 & $0.21-0.018$ & $0.71-0.059$ & 1.2 \\
\hline Ethylbenzene & 19.3 & $10.2-83.3$ & 0.9996 & $0.26-0.022$ & $0.86-0.072$ & 2.7 \\
\hline$p$-xylene & 19.9 & $10.2-83.4$ & 0.9994 & $0.25-0.021$ & $0.84-0.070$ & 3.8 \\
\hline m-xylene & 20.5 & $10.2-82.7$ & 0.9985 & $0.26-0.022$ & $0.85-0.071$ & 1.9 \\
\hline$o$-xylene & 23.4 & $10.3-84.0$ & 0.9995 & $0.25-0.021$ & $0.85-0.071$ & 0.8 \\
\hline d-Limonene & 23.9 & $9.6-78.2$ & 0.9996 & $0.28-0.023$ & $0.93-0.078$ & n.d. \\
\hline Styrene & 28.6 & $9.8-74.1$ & 0.9967 & $0.15-0.013$ & $0.50-0.042$ & n.d. \\
\hline EGBE & 35.6 & $10.6-86.7$ & 0.9990 & $0.25-0.021$ & $0.82-0.068$ & 4.5 \\
\hline 2-Ethylhexanol & 37.9 & $10.6-86.1$ & 0.9950 & $0.14-0.012$ & $0.47-0.039$ & 12.2 \\
\hline Benzyl alcohol & 46.7 & $11.7-95.0$ & 0.9986 & $0.22-0.018$ & $0.74-0.062$ & n.d. \\
\hline
\end{tabular}

Linearity and sensitivity. For each compound of interest, the method linearity was evaluated within the mass ranges reported in Table 3. All VOCs exhibited satisfactory results, with correlation coefficients $\left(\mathrm{R}^{2}\right)$ of the multi-point calibrations always $>0.99$ (Table 3). LOD and LOQ values calculated as mass (ng) and concentration in air $\left(\mu \mathrm{g} / \mathrm{m}^{3}\right)$ are shown in Table 3. Results for our GC-FID method were slightly higher than those reported in other studies using GC-MS instrumentation, as expected [27,30]. Despite this, these figures would enable the quantitative determination for all the analytes of interest at the concentration levels typically expected in real samples for the investigated indoor environments.

Tube desorption evaluation. To evaluate the performance of VOCs desorption process from Tenax tubes, a subsequent re-analysis of the already desorbed tubes was carried out, both with spiked tubes and sampled tubes, in order to verify the effective complete desorption and, if necessary, remove any remaining analytes. A desorption efficiency $>98 \%$ was accounted for all the investigated compounds. The GC chromatograms obtained from a subsequent GC analysis of Tenax tubes after desorption were indeed comparable to the blanks performed on the same tubes immediately prior to their use.

Inter-tubes variability. The whole measurement method-from ambient sampling to quantitative analysis-was assessed by calculating the percent relative standard deviation (\%RSD) of concentration levels obtained from parallel measurements on four Tenax tubes exposed at an outdoor urban background site. Results revealed very low inter-tubes variability for all the investigated pollutants, with RSDs quite always lower than 5\% (Table 3). Slightly higher values, although in a satisfactory range, were found for benzene (10.4\%) and 2-ethylhexanol (12.2\%). This could be attributable to the 
presence of other peaks-probably due to solvent impurities or substances released from Tenax at high temperatures-which eluted in the immediate vicinity of the target molecules, and made inhibited the integration of peak areas, albeit in an insignificant way.

\subsection{Vocs Concentrations in Residential Buildings}

All the target compounds were quantified above their respective LOQs, with the exception of styrene and benzyl alcohol, that were not detected in the indoor air of two ambient samples. The statistic parameters associated with the mean, standard deviation, median, minimum and maximum values for the investigated pollutants are presented in Table 4.

Table 4. Summary statistics for all the selected VOCs during the dishwasher washing cycle (n: number of samples; S.D.: Standard Deviation). The Derived No-Effect Levels (DNELs) related to short-term and long-term effects for the general population are also reported.

\begin{tabular}{|c|c|c|c|c|c|c|}
\hline Compound & $\mathbf{n}$ & $\begin{array}{c}\text { Mean (S.D.) } \\
\left(\mu \mathrm{g} / \mathrm{m}^{3}\right)\end{array}$ & $\begin{array}{l}\text { Median } \\
\left(\mu \mathrm{g} / \mathrm{m}^{3}\right)\end{array}$ & $\begin{array}{c}\operatorname{Min}-M a x \\
\left(\mu \mathrm{g} / \mathrm{m}^{3}\right)\end{array}$ & $\begin{array}{c}\text { DNELs- } \\
\text { Short-Term }\left(\mathrm{mg} / \mathrm{m}^{3}\right)\end{array}$ & $\begin{array}{c}\text { DNELs - Long-Term } \\
\left(\mathrm{mg} / \mathrm{m}^{3}\right)\end{array}$ \\
\hline Benzene & 9 & $4.0(2.5)$ & 2.8 & $1.8-9.3$ & / & / \\
\hline$\alpha$-Pinene & 9 & $6.2(10.3)$ & 2.8 & $1.2-33.1$ & / & 5.69 \\
\hline Toluene & 9 & $23.4(23.3)$ & 13.4 & $3.2-63.1$ & 384 & 192 \\
\hline Ethylbenzene & 9 & $4.8(4.0)$ & 3.1 & $1.2-13.1$ & / & 15 \\
\hline p-xylene & 9 & $4.3(5.0)$ & 2.0 & $0.7-16.5$ & 260 & 65 \\
\hline$m$-xylene & 9 & $13.8(11.6)$ & 12.4 & $1.7-38.6$ & 260 & 65 \\
\hline$o$-xylene & 9 & $4.9(4.8)$ & 2.5 & $1.4-16.3$ & 260 & 65 \\
\hline d-Limonene & 9 & 231.5 (191.3) & 204.9 & $17.0-611.3$ & 66.7 & 3.6 \\
\hline Styrene & 9 & $0.9(0.5)$ & 0.9 & $<$ LOD-1.5 & 289 & 10.2 \\
\hline EGBE & 9 & $5.2(3.5)$ & 4.3 & $0.7-11.3$ & / & 98 \\
\hline 2-Ethylhexanol & 9 & $5.1(6.4)$ & 3.0 & $0.5-21.6$ & / & 12.8 \\
\hline Benzyl alcohol & 9 & $1.7(1.7)$ & 0.9 & $<$ LOD-5.0 & / & 22 \\
\hline
\end{tabular}

The most abundant VOC in all dwellings was d-limonene, which registered concentration levels often $>100 \mu \mathrm{g} / \mathrm{m}^{3}$, with a mean of $231 \mu \mathrm{g} / \mathrm{m}^{3}$ and a maximum equal to $611 \mu \mathrm{g} / \mathrm{m}^{3}$. This was expected, since the air monitoring was deliberately performed during the dishwasher washing cycle, and $\mathrm{d}$-limonene is frequently used as fragrance in dishwasher tablets or liquid detergents (Table 2) and in cleaning products in general because of its pleasant odor $[32,33,36]$.

All the other compounds were found at concentration levels one or two orders of magnitude lower than d-limonene, and ranged from $3.2-63.1 \mu \mathrm{g} / \mathrm{m}^{3}$ (toluene), $1.7-38.6 \mu \mathrm{g} / \mathrm{m}^{3}$ (m-xylene) to $<$ LOD-5.0 $\mu \mathrm{g} / \mathrm{m}^{3}$ (benzyl alcohol) and $<$ LOD- $1.5 \mu \mathrm{g} / \mathrm{m}^{3}$ (styrene). Benzene, ethylbenzene, $o$-, $p$-xylene, EGBE, 2-ethylhexanol, and $\alpha$-pinene showed comparable values, with average concentrations between 4.0 and $6.0 \mu \mathrm{g} / \mathrm{m}^{3}$ (Table 4 ).

Boxplots shown in Figure 1 provide a more detailed view about the variability in the indoor VOCs concentrations for the nine investigated homes. The highest 75 th percentile was observed for d-limonene, followed by toluene and $m$-xylene $\left(363.0,48.1\right.$ and $20.7 \mu \mathrm{g} / \mathrm{m}^{3}$, respectively). All the target compounds showed a certain concentration variability among homes (coefficients of variability always $>60 \%$ ) and, in some cases (e.g., $\alpha$-pinene, 2-ethylhexanol, $p$-xylene), the observed variability was emphasized by the presence of one or two concentrations in the data that were clearly higher than all the other corresponding values (Table 4 and Figure 1). Nevertheless, the available information (concerning, for example, the occupants' habits or the specific household activities carried out during sampling) were not enough to interpret and explain these higher values, which, anyway, have been reported in residential or other environments [3]. For this reason, all data were included and presented in Figure 1.

As previously stated, the high concentrations and variability shown for d-limonene could likely reflect the heterogeneous daily habits of occupants, in particular in their use of cleaning products during the dishwasher washing cycle and also for the general cleaning of homes and through the use of personal care products. 


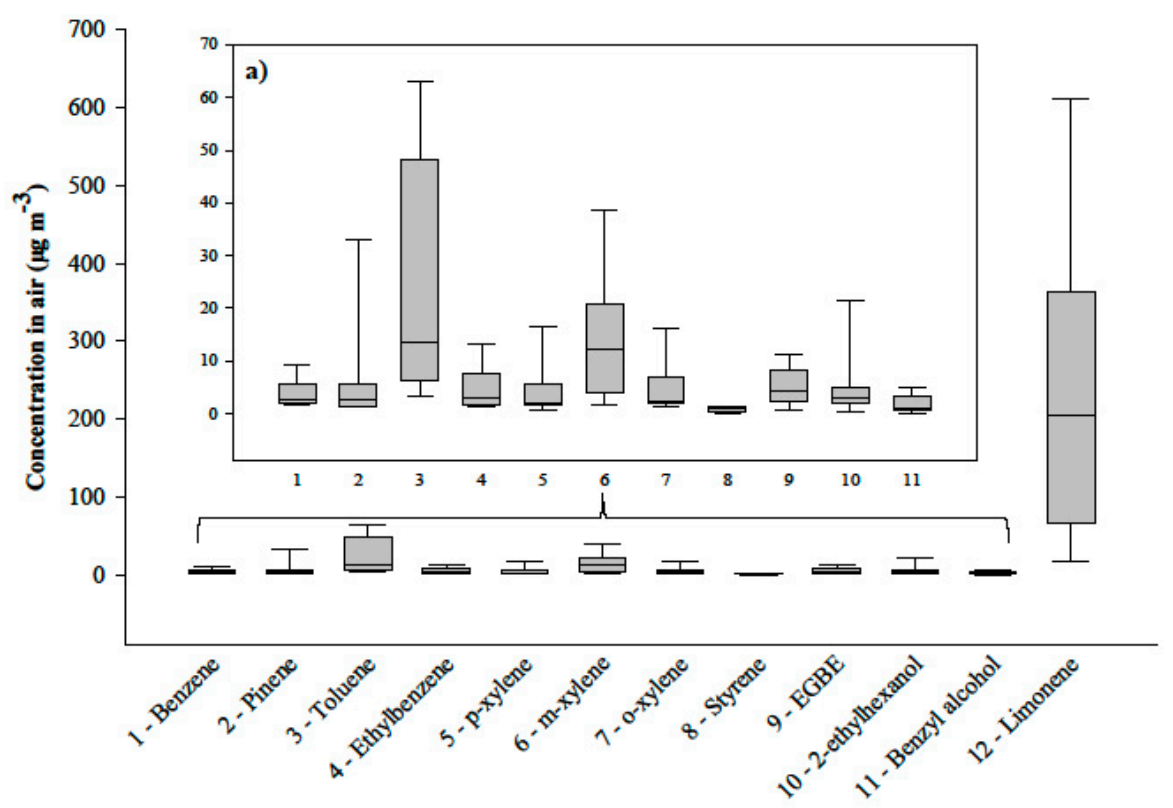

Figure 1. Variability in the indoor VOCs concentrations for the nine investigated homes during the dishwasher washing cycle (8 samples for styrene and benzyl alcohol, 9 samples for all the other compounds). The median, interquartile range and the maximum and minimum values are shown. Because of the great difference in the concentration ranges, VOCs 1-11 were also plotted in panel (a) excluding d-limonene.

Compounds including benzene, toluene, ethylbenzene and xylenes (BTEX) are generally ubiquitous in the indoor environment. The Spearman correlation analyses performed on the target pollutants considering the nine investigated homes always revealed high and statistically significant associations among BTEX (Spearman correlation coefficients $>0.75 ; p<0.02$ ), suggesting a potential common source for these compounds, which is most likely outdoor air pollution. Indeed, different studies clearly showed the great influence of outdoor emissions (e.g., fossil fuel combustion by traffic-related or industrial sources) on the indoor occurrence of these chemicals [37-39]. Nevertheless, at the same time, specific indoor sources of BTEX may also exist. Benzene has been widely used as an industrial solvent in paints and varnishes, and the most relevant indoor sources are tobacco smoke and incense burning [40]. Toluene was found in a variety of household products such as paints, cleaning agents, adhesives, nail polishes and other cosmetics. Xylenes are widely used in the chemical industry for products such as paints, inks, dyes, adhesives and detergents [41], and they are also emitted as result of cigarette smoking [40]. Also, styrene is a widely-used VOC in a number of products, such as plastics and almost all carpets that have a synthetic backing [42]. Ethylexhanol is a typical secondary VOC derived from the alkaline hydrolysis of some compounds (e.g., carboxylic acid esters and polymers) present in different materials as carpets and vinyl floorings [43,44].

In terms of health concerns, among all the target VOCs, only benzene is classified as human carcinogen of Group I (genotoxicity and acute myeloid leukemia) from the International Agency for Research on Cancer [14,45]. For this genotoxic compound, no safe levels of exposure can be recommended, and according to the WHO, the unit risk of leukemia per $1 \mu \mathrm{g} / \mathrm{m}^{3}$ of benzene in air is equal to $6 \times 10^{-6}$ [14]. Therefore, from a practical standpoint, since there is no known exposure threshold, it is expedient to reduce indoor exposure concentrations to as low as possible, by eliminating or at least reducing the human activities that release benzene (e.g., smoking tobacco). Also adequate ventilation systems could help to control the indoor penetration of outdoor benzene, for example, by positioning inlets for fresh air on the least polluted side of the building [14].

The other investigated compounds, such as terpenes and aromatic organic molecules, could cause irritant effects after dermal contact, and their inhalation may be related to respiratory endpoints like 
nose and throat irritation, palpitation, dizziness, chest pain, bronchitis or nephritis [46]. For such chemicals, specific WHO air quality guidelines are not available, but different health-based limit values above which humans should not be exposed to avoid the occurrence of such effects exist. Table 4 shows, for example, the available Derived No-Effect Levels (DNELs) related to short- and long-term exposure via the inhalation route for the general population (consumers and humans exposed via the environment) [47,48]. The field monitoring campaign presented in this paper was just a simple case-study, limited in terms of sampling period, number of samples and representativeness of indoor exposure levels. Nevertheless, obtained results (some $\mu \mathrm{g} / \mathrm{m}^{3}$ ) were always from three to four orders of magnitude lower than their respective DNELs (some $\mathrm{mg} / \mathrm{m}^{3}$ ) (Table 4).

In the framework of the EU EPHECT Project, a detailed health risk assessment was performed and health-based Critical Exposure Limits (CELs) were derived for five selected pollutants of respiratory health relevance, including $d$-limonene and $\alpha$-pinene [49]. Regarding d-limonene, a short-term CEL of $90 \mathrm{mg} / \mathrm{m}^{3}$ was established for sensory irritation, whereas the long-term limit of $9 \mathrm{mg} / \mathrm{m}^{3}$ was derived by extrapolation from short-term data, applying an assessment factor of 10 , following a conservative based-approach. For $\alpha$-pinene, the short-term and long-term CELs were established to be $45 \mathrm{mg} / \mathrm{m}^{3}$ and $4.5 \mathrm{mg} / \mathrm{m}^{3}$, respectively [49]. Also in this case, the concentration values obtained in our study for both compounds were well below the proposed CELs.

Nevertheless, in this regard, it is noteworthy that the concentrations of terpenes, although well below the derived DNELs or CELs, should not be totally underestimated-especially in the case of d-limonene-because of the possible gas-phase reactions which these compounds can readily undergo in the presence of ozone, with the formation of different chemical species which are potentially harmful for the human respiratory health [6,50]. Indeed, as explained in the introduction section, terpenes-and, for instance, limonene-are able to rapidly react with ozone in the atmosphere to produce a complex mixture of gaseous oxygenated compounds like formaldehyde, acetone and hydrogen peroxide, as well as different gases having a low vapor pressure (e.g., multifunctional carbonyls and acids). The low vapor gases can subsequently self-nucleate to generate ultrafine particles $(<0.1 \mu \mathrm{m})$ or condense on existing larger particles, leading to the formation of secondary organic aerosols (SOAs) $[6,7,50]$.

\subsection{Comparison of Vocs Concentrations with Other Studies}

VOC concentrations from some previous studies performed in residential buildings worldwide are presented in Table 5. Unlike our survey, in which a specific case-study related to short-term exposure to dish washer emissions was examined, the reported investigations generally referred to long sampling intervals (from some hours to some days), because this approach is generally assumed to be more representative of the actual personal exposure than short-term measurements. Moreover, looking at the scientific literature, similar investigations on IAQ during and following dishwasher cycles were not found. Therefore, from this point of view, the comparison could be somewhat impaired, at least for those chemical species whose concentration levels are expected to be influenced by this type of domestic activity.

Regarding terpene compounds, $\mathrm{d}$-limonene and $\alpha$-pinene can be found in the literature in a wide range of concentrations, with mean values that can vary from few to hundreds of $\mu \mathrm{g} / \mathrm{m}^{3}$. In a large survey performed in England, Raw and collaborators registered concentrations of d-limonene from 0.1 to $308 \mu \mathrm{g} / \mathrm{m}^{3}$, with an average geometric mean of $6.2 \mu \mathrm{g} / \mathrm{m}^{3}$ [51]. A more recent study carried out in English residential buildings showed concentration values between 18 and $1439 \mu \mathrm{g} / \mathrm{m}^{3}$, with one of the highest domestic values reported in the literature for d-limonene [4]. 
Table 5. Indoor VOCs concentrations measured in residential buildings from some previous investigations.

\begin{tabular}{|c|c|c|c|c|c|c|c|c|c|c|c|c|}
\hline \multirow{3}{*}{ Reference } & \multirow{3}{*}{ Location } & \multirow{3}{*}{ Sampling Information } & \multicolumn{10}{|c|}{ Mean [Median] $\left(\mu \mathrm{g} / \mathrm{m}^{3}\right)$} \\
\hline & & & \multicolumn{10}{|c|}{$(\operatorname{Min}-M a x)$ or $(\operatorname{Max})\left(\mu \mathrm{g} / \mathrm{m}^{3}\right)$} \\
\hline & & & Benzene & $\alpha$-Pinene & Toluene & Ethylbenzene & $p$-xylene & $m$-xylene & $o$-xylene & d-Limonene & Styrene & 2-Ethylhexanol \\
\hline $\begin{array}{l}\text { This } \\
\text { study }\end{array}$ & Como (Italy) & $\begin{array}{l}2 \mathrm{~h} \text { sampling during the dishwasher } \\
\text { washing cycle }\end{array}$ & $\begin{array}{l}4.0[2.8] \\
(1.8-9.3)\end{array}$ & $\begin{array}{c}6.2[2.8] \\
(1.2-33.1)\end{array}$ & $\begin{array}{l}23.4[13.4] \\
(3.2-63.1)\end{array}$ & $\begin{array}{c}4.8[3.1] \\
(1.2-13.1)\end{array}$ & $\begin{array}{c}4.3[2.0] \\
(0.7-16.5)\end{array}$ & $\begin{array}{l}13.8[12.4] \\
(1.7-38.6)\end{array}$ & $\begin{array}{c}4.9[2.5] \\
(1.4-16.3)\end{array}$ & $\begin{array}{l}231.5 \text { [204.9] } \\
(17.0-611.3)\end{array}$ & $\begin{array}{c}0.9[0.9] \\
(<\text { LOD-1.5) }\end{array}$ & $\begin{array}{c}5.1[3.0] \\
(0.5-21.6)\end{array}$ \\
\hline [4] & York (UK) & 5-days sampling in homes & $(7-19)$ & $(2-229)$ & & & & & & $(18-1439)$ & & \\
\hline [18] & $\begin{array}{l}\text { Different cities } \\
\text { across Europe }\end{array}$ & 7-days sampling in homes & $\begin{array}{c}2.8[1.9] \\
(0.4-32.1)\end{array}$ & $\begin{array}{c}14.5[6.1] \\
(0.2-214.1)\end{array}$ & $\begin{array}{c}11.7[6.5] \\
(1.3-160.6)\end{array}$ & $\begin{array}{c}1.5[1.1] \\
(0.2-12.8)\end{array}$ & \multicolumn{2}{|c|}{$\begin{array}{c}3.8[2.8] \\
(0.5-28.1)\end{array}$} & $\begin{array}{c}1.8[1.2] \\
(0.2-20.5)\end{array}$ & $\begin{array}{l}29.2[9.5] \\
(0-492.9)\end{array}$ & $\begin{array}{c}0.4[0] \\
(0-22.1)\end{array}$ & \\
\hline [37] & $\begin{array}{l}\text { Helsinki } \\
\text { (Finland) }\end{array}$ & $\begin{array}{l}48 \mathrm{~h} \text { sampling in residential indoor } \\
\text { microenvironments }\end{array}$ & $\begin{array}{c}2.2 \\
(14.1)\end{array}$ & $\begin{array}{c}16.1 \\
(215.6)\end{array}$ & $\begin{array}{c}20.4 \\
(247.4)\end{array}$ & $\begin{array}{c}2.9 \\
(19.0)\end{array}$ & \multicolumn{2}{|c|}{$\begin{array}{c}7.8 \\
(62.5)\end{array}$} & $\begin{array}{c}2.5 \\
(23.9)\end{array}$ & $\begin{array}{c}31.6 \\
(494.9)\end{array}$ & $\begin{array}{c}1.2 \\
(15.2)\end{array}$ & $\begin{array}{c}3.7 \\
(34.3)\end{array}$ \\
\hline [38] & Michigan (USA) & 4-days sampling in living room & $\begin{array}{c}2.8[1.2] \\
(47.4)\end{array}$ & $\begin{array}{l}9.0[3.2] \\
(139.2)\end{array}$ & $\begin{array}{c}15.6[6.8] \\
(197.3)\end{array}$ & $\begin{array}{l}2.2[1.0] \\
(79.9)\end{array}$ & \multicolumn{2}{|c|}{$\begin{array}{l}7.9[3.3] \\
(318.7)\end{array}$} & $\begin{array}{l}2.4[1.1] \\
(50.4)\end{array}$ & $\begin{array}{l}25.7[16.6] \\
(258.5)\end{array}$ & $\begin{array}{c}0.5[0.3] \\
(6.6)\end{array}$ & \\
\hline [51] & England & $\begin{array}{l}\text { 4-weeks sampling in the bedroom of } \\
\text { each home }\end{array}$ & $\begin{array}{c}3.0 \\
(<0.1-93.5)\end{array}$ & & $\begin{array}{c}15.1 \\
(0.3-1783.5)\end{array}$ & & \multicolumn{2}{|c|}{$\begin{array}{c}(318.7) \\
3.8 \\
(0.1-152.8)\end{array}$} & & $\begin{array}{c}6.2 \\
(<0.1-308.4)\end{array}$ & & \\
\hline [52] & $\begin{array}{l}\text { Puertollano } \\
\text { (Spain) }\end{array}$ & 2-weeks sampling in living rooms & $\begin{array}{l}1.9[1.7] \\
(0.7-5.1)\end{array}$ & $\begin{array}{l}18.5[13.4] \\
(2.5-63.1)\end{array}$ & $\begin{array}{l}12.0[6.3] \\
(2.6-87.9)\end{array}$ & $\begin{array}{l}3.4[2.7] \\
(0.7-13)\end{array}$ & \multicolumn{2}{|c|}{$\begin{array}{c}7.0[4.7] \\
(1.6-20.4)\end{array}$} & $\begin{array}{c}0.8[0.4] \\
(<\text { LOD-3.1) }\end{array}$ & $\begin{array}{l}17.1[13.4] \\
(1.8-87.2)\end{array}$ & $\begin{array}{l}2.1[1.9] \\
(0.3-6.5)\end{array}$ & \\
\hline [53] & $\begin{array}{l}\text { Different cities } \\
\text { in Germany }\end{array}$ & $\begin{array}{l}\text { 4-weeks sampling in different } \\
\text { residential rooms }\end{array}$ & $\begin{array}{c}3.2[2.3] \\
(12.0)\end{array}$ & $\begin{array}{c}23.3[9.8] \\
(141.8)\end{array}$ & $\begin{array}{c}29.5[18.3] \\
(142.9)\end{array}$ & $\begin{array}{c}3.6[1.9] \\
(19.1)\end{array}$ & \multicolumn{2}{|c|}{$\begin{array}{c}9.8[4.6] \\
(47.9)\end{array}$} & $\begin{array}{c}2.7[1.4] \\
(15.3)\end{array}$ & $\begin{array}{c}32.9[16.0] \\
(172.5)\end{array}$ & $\begin{array}{c}1.4[0.6] \\
(8.8)\end{array}$ & \\
\hline [54] & Oxford (UK) & $\begin{array}{l}48 \mathrm{~h} \mathrm{sampling} \mathrm{in} \mathrm{residential} \mathrm{indoor} \\
\text { microenvironments }\end{array}$ & 3.6 & 16.5 & 23.7 & 2.9 & \multicolumn{2}{|c|}{9.0} & & 19.0 & & \\
\hline [55] & $\begin{array}{l}\text { Hamburg } \\
\text { (Germany) } \\
\text { Erfurt } \\
\text { (Germany) }\end{array}$ & $\begin{array}{l}\text { 1-week sampling in living room and } \\
\text { bedroom } \\
\text { 1-week sampling in living room and } \\
\text { bedroom }\end{array}$ & {$[1.5]$} & & {$[20.5]$} & {$[0.7]$} & \multicolumn{2}{|c|}{ [2.9] } & {$[0.8]$} & & & \\
\hline [56] & $\begin{array}{l}\text { La Plata } \\
\text { (Argentina) }\end{array}$ & $\begin{array}{l}\text { 4-weeks sampling in homes at an } \\
\text { urban area }\end{array}$ & $\begin{array}{c}3.6[3.2] \\
(12.7)\end{array}$ & & $\begin{array}{c}15.1[11.7] \\
(89.0)\end{array}$ & $\begin{array}{l}1.4[1.3] \\
(2.9)\end{array}$ & \multicolumn{2}{|c|}{$\begin{array}{c}6.5[6.3] \\
(18.8)\end{array}$} & $\begin{array}{c}1.6[1.4] \\
(4.8)\end{array}$ & & $\begin{array}{c}0.3[0.2] \\
(0.7)\end{array}$ & \\
\hline
\end{tabular}


In the AIRMEX study, the authors identified $\alpha$-pinene and d-limonene as being predominantly derived from indoor sources, with mean concentrations of 14.5 and $29.2 \mu \mathrm{g} / \mathrm{m}^{3}$ observed in homes, respectively [18]. Similarly, 22 studied homes in Puertollano, Spain, registered average concentrations of d-limonene and $\alpha$-pinene equal to 17.1 and $18.5 \mu \mathrm{g} / \mathrm{m}^{3}$ respectively [52], while in 53 indoor environments in Michigan, d-limonene was monitored with mean and maximum values of 25.7 and $258.5 \mu \mathrm{g} / \mathrm{m}^{3}$ [38]. Also Schlink et al. observed in German residential rooms a mean value of d-limonene equal to $32.9 \mu \mathrm{g} / \mathrm{m}^{3}$ [53]. In our survey, the average level monitored for d-limonene was generally one order of magnitude higher $\left(231.5 \mu \mathrm{g} / \mathrm{m}^{3}\right)$ than those in the cited literature because of the experimental approach used, which led this result to be more representative of short-term peak concentrations reached during a specific household activity.

For all other compounds, the indoor measurements in Como homes were generally in the same range of other cities around the world [37,53-55]. Only indoor concentrations of toluene were slightly higher than those registered in Spain [52], Argentina [56] and in different cities across Europe [18] (Table 5).

\subsection{Strengths and Limitations of the Study}

As extensively highlighted in the scientific literature, research is needed to evaluate potential risks associated with the inhalation exposure to consumer products, to protect and promote health and well-being in indoor environments. Moreover, it is also underlined that product emission rates, but also typical household uses, should be investigated, following not only the combined use of consumer products during the day but also any single product use, in order to obtain an accurate risk assessment in case of consumer products [49].

The present work focused on the specific use of cleaning agents which, to our knowledge, has never been examined before as an individual case-study in terms of potential exposure to indoor volatile compounds.

Nevertheless, the experimental design is affected by some drawbacks and a lack of background information, which did not allow us to provide quantitative relationships or estimations (about the indoor VOCs variability, for example). The nine investigated homes were randomly selected, without considering differences in house location, house design and ventilation systems. Information concerning the occupants' habits, the specific household activities carried out during sampling; as well as outdoor measurements, air exchange rates and deposition factors were not gathered. The number of collected samples was limited. Finally, from an analytical point of view, more in-lab experiments and inter-laboratory comparisons should be added to better assess the method's reproducibility, precision and accuracy.

Therefore, for all these reasons, the obtained results should be taken as part of an exploratory survey, which could represent the starting point for more in-depth IAQ investigations. Moreover, relevant information in terms of short-term exposure to irritants could also be obtained from punctual peaks of concentrations, for which direct-reading instruments and lower time-resolution studies would be optimal.

\section{Conclusions}

In the present paper, a preliminary and general overview of concentration levels for 12 selected VOCs in the air of residential buildings during the dishwasher washing cycle was provided. The selectivity, sensitivity and desorption performance of the TD-GC-FID method optimized in this study allowed a reliable quantitative analysis of indoor air samples. d-Limonene was clearly identified as the most abundant molecule, with concentration values being two to three times higher than those of all the other gaseous pollutants; furthermore, a large degree variability was observed among the different environments. In general, the investigated VOCs were found at average concentration levels comparable to those of other places around the world-with the exception of d-limonene-and were below the respective safe levels for the general population. 
Because of the great importance that the monitoring of indoor VOCs may represent for the exposure assessment of workers and/or the general population, other investigations dealing with specific indoor emission sources are recommended. Moreover, given the complexity of the air chemical mixture and the ever-changing market of consumer products and building materials, the identification and quantification of less common and/or emerging compounds in specific environmental settings could be another key step to assessing potential health risks and to identifying the most appropriate risk management strategies when necessary.

Author Contributions: Conceptualization, S.R., A.C. and C.D.; Investigation, S.R. and A.F.; Methodology, S.R., A.C. and C.D.; Supervision, C.D.; Validation, S.R.; Writing-original draft, S.R.; Writing-review \& editing, A.C., A.F., A.S., F.B., D.C., C.D. and D.M.C.

Funding: This work was not financially supported by any dedicated funding and it was carried out with free available funds.

Acknowledgments: The authors would like to extend a special acknowledgement to Rossella Perna for her precious support during laboratory analyses of atmospheric samples.

Conflicts of Interest: The authors declare no conflicts of interest.

\section{References}

1. Schweizer, C.; Edwards, R.; Bayer-Oglesby, L.; Gauderman, W.; Ilacqua, V.; Jantunen, M.; Lai, H.; Nieuwenhuijsen, M.; Kunzli, N. Indoor time-microenvironment-activity patterns in seven regions of Europe. J. Expo. Sci. Environ. Epidemiol. 2007, 17, 170-181. [CrossRef] [PubMed]

2. Nørgaard, A.W.; Kofoed-Sørensen, V.; Mandin, C.; Ventura, G.; Mabilia, R.; Perreca, E.; Cattaneo, A.; Spinazzè, A.; Mihucz, V.G.; Szigeti, T.; et al. Ozone-initiated terpene reaction products in five European offices: Replacement of a floor cleaning agent. Environ. Sci. Technol. 2014, 48, 13331-13339. [CrossRef] [PubMed]

3. Mandin, C.; Trantallidi, M.; Cattaneo, A.; Canha, N.; Mihucz, V.G.; Szigeti, T.; Mabilia, R.; Perreca, E.; Spinazzè, A.; Fossati, S.; et al. Assessment of indoor air quality in office buildings across Europe-The OFFICAIR study. Sci. Total Environ. 2017, 579, 169-178. [CrossRef] [PubMed]

4. Wang, C.M.; Barratt, B.; Carslaw, N.; Doutsi, A.; Dunmore, R.E.; Ward, M.W.; Lewis, A.C. Unexpectedly high concentrations of monoterpenes in a study of UK homes. Environ. Sci. Process Impacts 2017, 19, $528-537$. [CrossRef] [PubMed]

5. Atkinson, R.; Arey, J. Atmospheric degradation of volatile organic compounds. Chem. Rev. 2003, 103, 4605-4638. [CrossRef] [PubMed]

6. Walser, M.L.; Desyaterik, Y.; Laskin, J.; Laskin, A.; Nizkorodov, S.A. High-resolution mass spectrometric analysis of secondary organic aerosol produced by ozonation of limonene. Phys. Chem. Chem. Phys. 2008, 10, 1009-1022. [CrossRef] [PubMed]

7. Rohr, A.C. The health significance of gas- and particle-phase terpene oxidation products: A review. Environ. Int. J. 2013, 60, 145-162. [CrossRef]

8. Wells, J.R.; Ham, J.E. A new agent for derivatizing carbonyl species used to investigate limonene ozonolysis. Atmos. Environ. 2014, 99, 519-526. [CrossRef]

9. Carslaw, N. A new detailed chemical model for indoor air pollution. Atmos. Environ. 2007, 41, 1164-1179. [CrossRef]

10. Stone, D.; Whalley, L.K.; Heard, D.E. Tropospheric $\mathrm{OH}$ and $\mathrm{HO}_{2}$ radicals: Field measurements and model comparisons. Chem. Soc. Rev. 2012, 41, 6348-6404. [CrossRef]

11. Carslaw, N.; Fletcher, L.; Heard, D.; Ingham, T.; Walker, H. Significant OH production under surface cleaning and air cleaning conditions: Impact on indoor air quality. Indoor Air 2017, 27, 1091-1100. [CrossRef] [PubMed]

12. Koistinen, K.; Kotzias, D.; Kephalopoulos, S.; Schlitt, C.; Carrer, P.; Jantunen, M.; Kirchner, S.; McLaughlin, J.; Mølhave, L.; Fernandes, E.O.; et al. The INDEX project: Executive summary of a European Union project on indoor air pollutants. Allergy 2008, 63, 810-819. [CrossRef] [PubMed]

13. Wolkoff, P. Indoor air pollutants in office environments: Assessment of comfort, health and performance. Int. J. Hyg. Environ. Health 2013, 216, 371-394. [CrossRef] [PubMed] 
14. World Health Organization (WHO), Regional Office for Europe. Guidelines for Indoor Air Quality: Selected Pollutants; WHO: Copenhagen, Denmark, 2010.

15. Cacho, C.; Ventura Silva, G.; Martins, A.O.; Fernandes, E.O.; Saraga, D.E.; Dimitroulopoulou, C.; Bartzis, J.G.; Rembges, D.; Barrero-Moreno, J.; Kotzias, D. Air pollutants in office environments and emissions from electronic equipment: A review. Fresen. Environ. Bull. 2013, 22, 2488-2497.

16. Wilke, O.; Jann, O.; Broedner, D. VOC- and SVOC- emissions from adhesives, floor coverings and complete floor structures. Indoor Air 2004, 14, 98-107. [CrossRef] [PubMed]

17. Missia, D.A.; Demetriou, E.; Michale, N.; Tolis, E.I.; Bartzis, J.G. Indoor exposure from building materials: A field study. Atmos. Environ. 2010, 44, 4388-4395. [CrossRef]

18. Geiss, O.; Giannopoulos, G.; Tirendi, S.; Barrero-Moreno, J.; Larsen, B.R.; Kotzias, D. The AIRMEX study-VOC measurement in public buildings and schools/kindergartens in eleven European cities: Statistical analysis of the data. Atmos. Environ. 2011, 45, 3676-3684. [CrossRef]

19. Hanninen, O.O.; Alm, S.; Katsouyanni, K.; Künzli, N.; Maroni, M.; Nieuwenhuijsen, M.J.; Saarela, K.; Srám, R.J.; Zmirou, D.; Jantunen, M.J. The EXPOLIS study: Implications for exposure research and environmental policy in Europe. J. Expo. Anal. Environ. Epidemiol. 2004, 14, 440-456. [CrossRef] [PubMed]

20. Schlink, U.; Thiem, A.; Kohajda, T.; Richter, M.; Strebel, K. Quantile regression of indoor air concentrations of volatile organic compounds (VOC). Sci. Total Environ. 2010, 408, 3840-3851. [CrossRef] [PubMed]

21. Weschler, C.J. Changes in indoor pollutants since the 1950s. Atmos. Environ. 2009, 43, 153-169. [CrossRef]

22. Dunagan, S.C.; Dodson, R.E.; Rudel, R.A.; Brody, J.G. Toxics use reduction in the home: Lessons learned from household exposure studies. J. Clean. Prod. 2011, 19, 438-444. [CrossRef] [PubMed]

23. Hanninen, O.O.; Alm, S.; Kaarakainen, E.; Jantunen, M. The EXPOLIS Databases, B13/2002; Publications of the National Public Health Institute: Kuopio, Finland, 2002.

24. Stranger, M.; Potgieter-Vermaak, S.S.; Van Grieken, R. Comparative overview of indoor air quality in Antwerp, Belgium. Environ. Int. 2007, 33, 789-797. [CrossRef] [PubMed]

25. McClenny, W.A.; Coløn, M. Measurement of volatile organic compounds by the US Environmental Protection Agency Compendium Method TO-17 Evaluation of performance criteria. J. Chromatogr. A 1998, 813, 101-111. [CrossRef]

26. Peng, C.-Y.; Batterman, S. Performance evaluation of a sorbent tube sampling method using short path thermal desorption for volatile organic compunds. J. Environ. Monit. 2000, 2, 313-324. [CrossRef] [PubMed]

27. Sin, D.W.; Wong, Y.; Sham, W.; Wang, D. Development of an analytical technique and stability evaluation of 143 C3-C12 volatile organic compounds in Summa ${ }^{\circledR}$ canister by gas chromatography-mass spectrometry. Analyst 2001, 126, 310-321. [CrossRef] [PubMed]

28. Wu, C.-H.; Lin, M.-N.; Feng, C.-T.; Yang, K.-L.; Lo, Y.-S.; Lo, J.-G. Measurement of toxic volatile organic compounds in indoor air of semiconductor foundries using multisorbent adsorption/thermal desorption coupled with gas chromatography-mass spectrometry. J. Chromatogr. A 2003, 996, 225-231. [CrossRef]

29. Kuntasal, Ö.-O.; Karman, D.; Wang, D.; Tuncel, S.G.; Tuncel, G. Determination of volatile organic compounds in different microenvironments by multibed adsorbtion and short-path thermal desorption followed by gas chromatographic-mass spectrometry analysis. J. Chromatogr. A 2005, 1099, 43-54. [CrossRef]

30. Ribes, A.; Carrera, G.; Gallego, E.; Roca, X.; José Berenguer, M.; Guardino, X. Development and validation of a method for air-quality and nuisance odors monitoring of volatile organic compounds using multi-sorbent adsorption and gas chromatography/mass spectrometry thermal desorption system. J. Chromatogr. A 2007, 1140, 44-55. [CrossRef] [PubMed]

31. Kotzias, D.; Koistinen, K.; Kephalopoulos, S. The INDEX Project: Critical Appraisal of the Setting and Implementation of Indoor Exposure Limits in the EU; European Commision, Joint Research Center. Institute for Health and Consumer Protection: Ispra, Italy, 2005.

32. Howard-Reed, C.; Corsi, R.L. Mass transfer of volatile organic compounds from drinking water to indoor air: The role of residential dishwashers. Environ. Sci. Technol. 1999, 33, 2266-2272. [CrossRef]

33. Howard, C.; Corsi, R.L. Volatilization of chemicals from drinking water to indoor air: The role of residential washing machines. J. Air Waste Manag. 1998, 48, 907-914. [CrossRef]

34. Cocheo, C.; Boaretto, C.; Pagani, D.; Quaglio, F.; Sacco, P.; Zaratin, L.; Cottica, D. Field evaluation of thermal and chemical desorption BTEX radial diffusive sampler radiello ${ }^{\circledR}$ compared with active pumped (samplers) for ambient air measurements. J. Environ. Monit. 2009, 11, 297-306. [CrossRef] [PubMed] 
35. Ongwandee, M.; Moonrinta, R.; Panyametheekul, S.; Tangbanluekal, C.; Morrison, G. Investigation of volatile organic compounds in office buildings in Bangkok, Thailand: Concentrations, sources and occupant symptoms. Build. Environ. 2011, 46, 1512-1522. [CrossRef]

36. Uhde, E.; Schulz, N. Impact of room fragrance products on indoor air quality. Atmos. Environ. 2015, 106, 492-502. [CrossRef]

37. Edwards, R.D.; Jurvelin, J.; Saarela, K.; Jantunen, M. VOC concentrations measured in personal samples and residential indoor, outdoor and workplace microenvironments in EXPOLIS-Helsinki, Finland. Atmos. Environ. 2001, 35, 4531-4543. [CrossRef]

38. Jia, C.; Batterman, S.; Godwin, C. VOCs in industrial, urban and suburban neighborhoods, Part 1: Indoor and outdoor concentrations, variation, and risk drivers. Atmos. Environ. 2008, 42, 2083-2100. [CrossRef]

39. Campagnolo, D.; Saraga, D.E.; Cattaneo, A.; Spinazzè, A.; Mandin, C.; Mabilia, R.; Perreca, E.; Sakellaris, I.; Canha, N.; Mihucz, V.G.; et al. VOCs and aldehydes sources identification in European office buildings-The OFFICAIR study. Build. Environ. 2017, 115, 18-24. [CrossRef]

40. Kotzias, D.; Geiss, O.; Leva, P.; Belintani, A.; Arvanitis, A.; Kephalopoulos, S. Impact of various air exchange rates on the levels of environmental tobacco smoke (ETS) components. Fresen. Environ. Bull. 2004, 13, 1536-1549.

41. HSDB, Hazardous Substances Data Bank. Specialized Information Services. National Library of Medicine. 2003. Available online: https:/ / toxnet.nlm.nih.gov / (accessed on 10 October 2018).

42. Katsoyiannis, A.; Leva, P.; Kotzias, D. VOC and carbonyl emissions from carpets: A comparative study using four types of environmental chambers. J. Hazard. Mater. 2008, 152, 669-676. [CrossRef]

43. Yu, C.; Crump, D. A review of the emission of VOCs from polymeric materials used in buildings. Build. Environ. 1998, 33, 357-374. [CrossRef]

44. Uhde, E.; Salthammer, T. Impact of reaction products from building materials and furnishings on indoor air quality-A review of recent advances in indoor chemistry. Atmos. Environ. 2007, 41, 3111-3128. [CrossRef]

45. IARC Monographs on the Evaluation of Carcinogenic Risks to Humans; Overall Evaluation of Carcinogenity: An Updating of IARC Monographs Volumes 1 to 42. Suppl. 7; International Agency for Research on Cancer: Lyon, France, 1987; pp. 38-74.

46. Rohr, A.C.; Wilkins, C.K.; Clausen, P.A.; Hammer, M.; Nielsen, G.D.; Wolkoff, P.; Spengler, J.D. Upper airway and pulmonary effects of oxidation products of $(+)-\alpha$-pinene, d-limonene, and isoprene in BALB/c mice. Inhal. Toxicol. 2002, 14, 663-684. [CrossRef] [PubMed]

47. Petry, T.; Vitale, D.; Joachim, F.J.; Smith, B.; Cruse, L.; Mascarenhas, R.; Schneider, S.; Singal, M. Human health risk evaluation of selected VOC, SVOC and particulate emissions from scented candles. Regul. Toxicol. Pharm. 2014, 69, 55-70. [CrossRef] [PubMed]

48. ECHA. Guidance on Information Requirements and Chemical Safety Assessment. Chapter R.15: Consumer Exposure Assessment. European Chemicals Agency (Version 3.0). July 2016. Available online: https:/ / echa. europa.eu/documents/10162/13632/information_requirements_r15_en.pdf (accessed on 10 October 2018).

49. Trantallidi, M.; Dimitroulopoulou, C.; Wolkoof, P.; Kephalopoulos, S.; Carrer, P. EPHECT III: Health risk assessment of exposure to household consumer product. Sci. Total Environ. 2015, 536, 903-913. [CrossRef] [PubMed]

50. Nørgaard, A.W.; Kudal, J.D.; Kofoed-Sørensen, V.; Koponen, I.K.; Wolkoff, P. Ozone-initiated VOC and particle emissions from a cleaning agent and an air freshener: Risk assessment of acute airway effects. Environ. Int. 2014, 68, 209-218. [CrossRef] [PubMed]

51. Raw, G.J.; Coward, S.K.D.; Brown, V.M.; Crump, D.R. Exposure to air pollutants in English homes. J. Expo. Anal. Environ. Epidemiol. 2004, 14, S85-S94. [CrossRef] [PubMed]

52. Villanueva, F.; Tapia, A.; Amo-Salas, M.; Notario, A.; Cabañas, B.; Martínez, E. Levels and sources of volatile organic compounds including carbonyls in indoor air of homes in Puertollano, the most industrialized city in central Iberian Peninsula. Estimation of health risk. Int. J. Hyg. Environ. Health 2015, 218, 522-534. [CrossRef] [PubMed]

53. Schlink, U.; Rehwagen, M.; Damm, M.; Richter, M.; Borte, M.; Herbarth, O. Seasonal cycle of indoor-VOCs: Comparison of apartments and cities. Atmos. Environ. 2004, 38, 1181-1190. [CrossRef]

54. Lai, H.K.; Kendall, M.; Ferrier, H.; Lindup, I.; Alm, S.; Hanninen, O.; Jantunen, M.; Mathys, P.; Colvile, R.; Ashmore, M.R.; et al. Personal exposures and microenvironment concentrations of PM2.5, VOC, NO2 and CO in Oxford, UK. Atmos. Environ. 2004, 38, 6399-6410. [CrossRef] 
55. Schneider, P.; Gebefügi, I.; Richter, K.; Wölke, G.; Schnelle, J.; Wichmann, H.-E.; Heinrich, J.; INGA Study Group. Indoor and outdoor BTX levels in German cities. Sci. Total Environ. 2001, 267, 41-51. [CrossRef]

56. Massolo, L.; Rehwagen, M.; Porta, A.; Ronco, A.; Herbarth, O.; Mueller, A. Indoor-outdoor distribution and risk assessment of volatile organic compounds in the atmosphere of industrial and urban areas. Environ. Toxicol. 2010, 25, 339-349. [CrossRef]

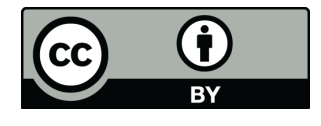

(C) 2019 by the authors. Licensee MDPI, Basel, Switzerland. This article is an open access article distributed under the terms and conditions of the Creative Commons Attribution (CC BY) license (http:/ / creativecommons.org/licenses/by/4.0/). 